\title{
Dill Is an Efficient Antioxidant Against ROS Specially Singlet Oxygen in the Oleic Acid Media
}

\author{
Mahdi Hajimohammadi* and Maryam Khalaji Verjani \\ Faculty of Chemistry, Kharazmi University, G. C, Mofateh, Tehran, 14911-15719, Iran
}

*Corresponding author: Mahdi Hajimohammadi, Faculty of Chemistry, Iran

\begin{abstract}
ARTICLE INFO
Received: 幽 September 25, 2019

Published: 幽 October 03, 2019

Citation: Mahdi Hajimohammadi, Maryam Khalaji Verjani. Dill Is an Efficient Antioxidant Against ROS Specially Singlet Oxygen in the Oleic Acid Media. Biomed J Sci \& Tech Res 21(5)-2019. BJSTR. MS.ID.003650.
\end{abstract}

Abbreviations: $\mathrm{OH}$ : Hydroxyl Radicals; BHA: Butylated Hydroxy anisole; BHT: Hydroxytoluene; TBHQ: Tert-Butyl Hydroquinone; PG: Propyl Gallate; ROS: Reactive Oxygen Species

\begin{abstract}
Scavenging of DPPH free radical is the basis of a common antioxidant assay and most often an overall antioxidant effect was measured. However, singlet oxygen $\left(10_{2}\right)$ has not radical nature and $10_{2}$ scavenging properties of natural antioxidants oppressed and less have been investigated. In this work effect of dill (Anethum graveolens L) as a natural antioxidant on fatty acid safety was investigated in the presence of $\mathrm{OH} \cdot \mathrm{H}_{2} \mathrm{O}_{2}$, $\mathrm{O}_{2}$ and specially $1 \mathrm{O}_{2}$. In order to evaluate antioxidant activities of dill extract, oleic acid oxidation was monitored by $1 \mathrm{H}$ NMR spectroscopy, peroxide value ( $\mathrm{PV}\left(\mathrm{meqO}_{2} / \mathrm{kg}\right)$ ) and UV-Vis spectroscopy. The rate of oleic acid oxidation by 102 as a very reactive ROS reduced about $42.5 \%$ in the presence of $2 \mathrm{~mL}$ methanolic extract of dill (contains 2.24 mg flavonoid compounds) as a natural antioxidant. This result reveals that dill has an efficient role on preservation of unsaturated fatty acids from photooxygenation. Also, UV-Vis spectroscopy as a reliable method to determine oleic acid oxidation showed in the oleic acid oxidation with $\mathrm{OH} \cdot$ and $\mathrm{H}_{2} \mathrm{O}_{2}$, bandgaps of oleic acid as a result of oxidation was compacted in the presence of dill which demonstrated dill is effective on control of fatty acid against these types of Reactive Oxygen Species (ROS).
\end{abstract}

Keywords: Reactive oxygen species; Oleic acid; Singlet oxygen; Dill antioxidant; Porphyrin sensitizers

\section{Introduction}

ROS such as Hydroxyl Radicals $(\mathrm{OH})$, Superoxide Anion $\left(\mathrm{O}_{2}\right)$, Hydrogen Peroxide $\left(\mathrm{H}_{2} \mathrm{O}_{2}\right)$ and singlet oxygen $\left(1 \mathrm{O}_{2}\right)$ are inevitable results of aerobic metabolism [1]. Because of high activity of ROS lipids, DNA and proteins can be their target [2] that caused many illnesses including cancer, cardiovascular disease, cataracts, Alzheimer's and aging [3,4]. Antioxidants are compounds that can delay, inhibit or prevent the oxidation by scavenging free radicals and diminish oxidative stress [5]. A trend toward the use of natural additives in foods has been apparent for quite some time as a result of consumer demand because safety of synthetic antioxidants such as Butylated Hydroxyanisole (BHA), Butylated Hydroxytoluene(BHT), Tert-Butyl Hydroquinone (TBHQ) and Propyl Gallate (PG) [6,7] has been questioned [8]. Recent research has focused on isolation and characterization of effective natural antioxidants [9-12]. Natural antioxidants act (a) as reducing agents, (b) as free radical scavengers, and (c) as quenchers of the formation of singlet oxygen. They can be used in the food industry and there is evidence that they may exert their antioxidant effects within the human body $[13,14]$. People receive antioxidant supplements directly from fresh fruits and vegetables. The World Health Organization estimated that $<80 \%$ of the earth's inhabitants rely on traditional medicine for their primary health care needs and most of this therapy involves the use of plant extracts or their active phenolic components [15] which have efficient antioxidant capacity. According to the published papers, the research on $\mathrm{OH}, \mathrm{H}_{2} \mathrm{O}_{2}$ and $\mathrm{O}$ as reactive oxygen species are widely carried out [16-18] whereas $10_{2}$ oppressed and less have been investigated because scavenging of DPPH free radical is the basis of a common antioxidant assay and most often an overall antioxidant effect was measured [19].

However, singlet oxygen has not radical nature. Oxygen molecule in its ground state has two unpaired electrons and when oxygen molecule has excess energy, these unpaired electrons in the external orbital can be pair and generate singlet oxygen [20]. One of the physical methods for producing singlet oxygen is applied photosensitizer. Great photosensitizers have received attention, due in part to their direct relevance to many biological systems. 
The photosensitized production of singlet oxygen has significance in the areas of the photooxidation of organic compounds, DNA damage and Photodynamic therapy [21-26]. electrophilic tendency of singlet oxygen causes lipids, amino acids, nucleic acids and electron rich molecular can be its target [27].This project was designed to characterize antioxidant potential of dill as a natural antioxidant due to its phenolic and flavonoids compositions and how its effect on toxic properties of different ROS specially singlet oxygen [28]. Oleic acid oxidation process was monitored by UV-Vis and $\mathrm{PV}\left(\mathrm{meqO}_{2} / \mathrm{Kg}\right)$ methods in the presence and absence of dill as an antioxidant and the results showed dill has efficient role to control oxidation process.

\section{Materials and Methods}

\section{Materials}

Oleic acid, ethanol, DMSO, hydrogen peroxide, acetonitrile and $\mathrm{KO}_{2}$ were purchased from Fluka and Merck without further purification. Tetraphenyl porphyrin ( $\left.\mathrm{H}_{2} \mathrm{TPP}\right), \mathrm{ZnTPP}$ and FeTPP and were synthesized according to the literatures [29]. Preparation of dill extract: Cold solvent extraction method was applied to separate the dill extract. Dill plant was dried, milled and then strained through sieve No. 40. Powdered form was mixed with solvent at $1: 10$ ratio on a shaker at room temperature for $24 \mathrm{~h}$ and then the mixture was filtered using filter paper and vacuum pump. The solvent was removed on a rotary evaporator under vacuum in order to minimize the loss. The remaining solvent was removed using nitrogen [30].

\section{Methods}

Sample preparation to oleic acid photooxygenation: $0.2 \mathrm{cc}$ photosensitizers $(0.001 \mathrm{M}), 1 \mathrm{cc}$ oleic acid were added to $5 \mathrm{cc}$ acetonitrile in a test tube. Reactions were irradiated with the sun simulator light (288 power LED lamps, 1W, 2.3V (59660 LUX)) for 6 hours at room temperature under $1 \mathrm{~atm}$ of bubbling of air in the solution. Sample preparation to oleic acid oxidation with $\mathrm{H}_{2} \mathrm{O}_{2}$ and $\mathrm{OH} \bullet$ for monitoring with UV-Vis method: $0.1 \mathrm{cc}$ hydrogen peroxide $30 \%$ and $0.1 \mathrm{cc}$ antioxidants (contains $0.4095 \mathrm{mg}$ polyphenolic compounds) were added to $5 \mathrm{cc}$ oleic acid $0.001 \mathrm{M}$. The reactions were irradiated by UV light from a high pressure 30W mercury lamp (Philips, $\boldsymbol{\lambda}=200-280 \mathrm{~nm}$ ) for $\mathrm{OH} \bullet$ generation. Sample preparation to oleic acid oxidation with $\mathrm{H}_{2} \mathrm{O}_{2}$ and $\mathrm{OH} \bullet$ by iodometric titration: $0.1 \mathrm{cc}$ hydrogen peroxide $30 \%$, 2cc oleic acid and 2cc antioxidant (contains $8.19 \mathrm{mg}$ polyphenolic compounds) added to $6 \mathrm{cc}$ ethanol. By irradiation of UV light from a high pressure 30W mercury lamp (Philips, $\boldsymbol{\lambda}=200-280 \mathrm{~nm}$ ) in the reactions $\mathrm{OH} \bullet$ is generated. In order to avoid interference of hydrogen peroxide in the PV (meq 02/ $\mathrm{kg}$ ) measurement, organic media which involves oleic acid oxidation products was extracted and work up by water and chloroform. Superoxide anion radical preparation for oleic acid oxidation: $2 \mathrm{cc}$ oleic acid and $0.44 \mathrm{gr} \mathrm{KO}_{2}$ added to $10 \mathrm{cc}$ DMSO in the presence of 3cc antioxidant (contains $12.285 \mathrm{mg}$ polyphenolic compounds).

\section{Analytical methods}

PV (meq $\mathrm{O}_{2} / \mathrm{kg}$ ) of the samples was determined according to the literature [31]. Oleic acid oxidation process was monitored by UV-Vis (Shimadzu 2100 spectrophotometer). 1H NMR spectra were obtained on a Bruker AMX $300 \mathrm{MHz}$ spectrometer using TMS as internal standard.

\section{Results and Discussion}

In this work the oxidative alterations of oleic acid as a result of oxidation with singlet oxygen, superoxide radical, hydrogen peroxide and radical hydroxyl were analyzed in the presence and absence of dill as a natural antioxidant due its phenolic compounds. Our target was fatty acid oxidation by different ROS with focus on singlet oxygen as a noble species which has worked few studies on it [19]. Photooxygenation of oleic acid with $\mathrm{H}_{2}$ TPP was investigated as a typical standard sample to evaluate singlet oxygen production (Scheme 1) and fatty acid oxidation monitored by iodometric method as a popular method. (Table 1) confirmed that singlet oxygen produced by applying different kind of photosensitizers. It is important to note that $1 \mathrm{H} \mathrm{NMR} \mathrm{(see} \mathrm{supporting} \mathrm{information)}$ and peroxide value the oxidation of oleic acid to peroxide product stopped in the absence of porphyrin (Table 1 entry 1) or when the irradiation was interrupted (Table 1 entry 2). Accordingly, the presence of a porphyrin, light and $\mathrm{O}_{2}$ are essential for the conversion oleic acid to corresponding products (Table 1 entry 3 ).

Table 1: PV number of oleic acid oxidation by singlet oxygen in different conditions.

\begin{tabular}{|c|c|c|}
\hline Entry & Condition & PV \\
\hline 1 & oleic acid $+\mathrm{CH}_{3} \mathrm{CN}+$ air + light & trace \\
\hline 2 & oleic acid $+\mathrm{CH}_{3} \mathrm{CN}+\mathrm{H}_{2} \mathrm{TPP}+$ air & trace \\
\hline 3 & oleic acid $+\mathrm{CH}_{3} \mathrm{CN}+\mathrm{H}_{2} \mathrm{TPP}+$ light + air & 283.14 \\
\hline 4 & oleic acid $+\mathrm{CH}_{3} \mathrm{CN}+\mathrm{H}_{2} \mathrm{TPP}+$ light + air + dill & 232.58 \\
\hline $5 \mathrm{~b}$ & oleic acid $+\mathrm{CH}_{3} \mathrm{CN}+\mathrm{H}_{2} \mathrm{TPP}+\mathrm{NaN}_{3}+$ light + & 49.43 \\
\hline 6 & oleic acid $+\mathrm{DMSO}+\mathrm{H}_{2} \mathrm{TPP}+$ light + air & 64.44 \\
\hline 7 & oleic acid $+\mathrm{C}_{2} \mathrm{H}_{5} \mathrm{OH}+\mathrm{H}_{2} \mathrm{TPP}+$ light + air & 258.42 \\
\hline 8 & oleic acid $+\mathrm{C}_{2} \mathrm{H}_{5} \mathrm{OH}+\mathrm{H}_{2} \mathrm{TPP}+$ light + air + dill & 126.96 \\
\hline 9 & oleic acid $+\mathrm{CH}_{3} \mathrm{CN}+\mathrm{ZnTPP}+$ light + air & 37.07 \\
\hline 10 & oleic acid $+\mathrm{CH}_{3} \mathrm{CN}+\mathrm{FeTPP}+$ light + air & 35.95 \\
\hline $11 \mathrm{c}$ & oleic acid $+\mathrm{CH}_{3} \mathrm{CN}+\mathrm{H}_{2} \mathrm{TPP}+$ light + air + dill & 202.2 \\
\hline $12 \mathrm{~d}$ & oleic acid $+\mathrm{CH}_{3} \mathrm{CN}+\mathrm{H}_{2} \mathrm{TPP}+$ light + air + dill & 162.92 \\
\hline
\end{tabular}

a) $3.1 \times 10^{-3} \mathrm{~mol}$ oleic acid, $0.5 \mathrm{cc}$ antioxidant (contains 0.56 $\mathrm{mg}$ flavonoid), 5cc solvent, $0.2 \mathrm{cc}(0.001 \mathrm{M})$ sensitizer, air (1atm) and 288 power LED lamps, 1 W, 2.3 V (59660 LUX).

b) $0.01 \mathrm{gr}$ sodium azide applied as singlet oxygen scavenger.

c) $1 \mathrm{cc}$ antioxidant (contains $1.12 \mathrm{mg}$ flavonoid).

d) 2cc antioxidant (contains $2.24 \mathrm{mg}$ flavonoid). 


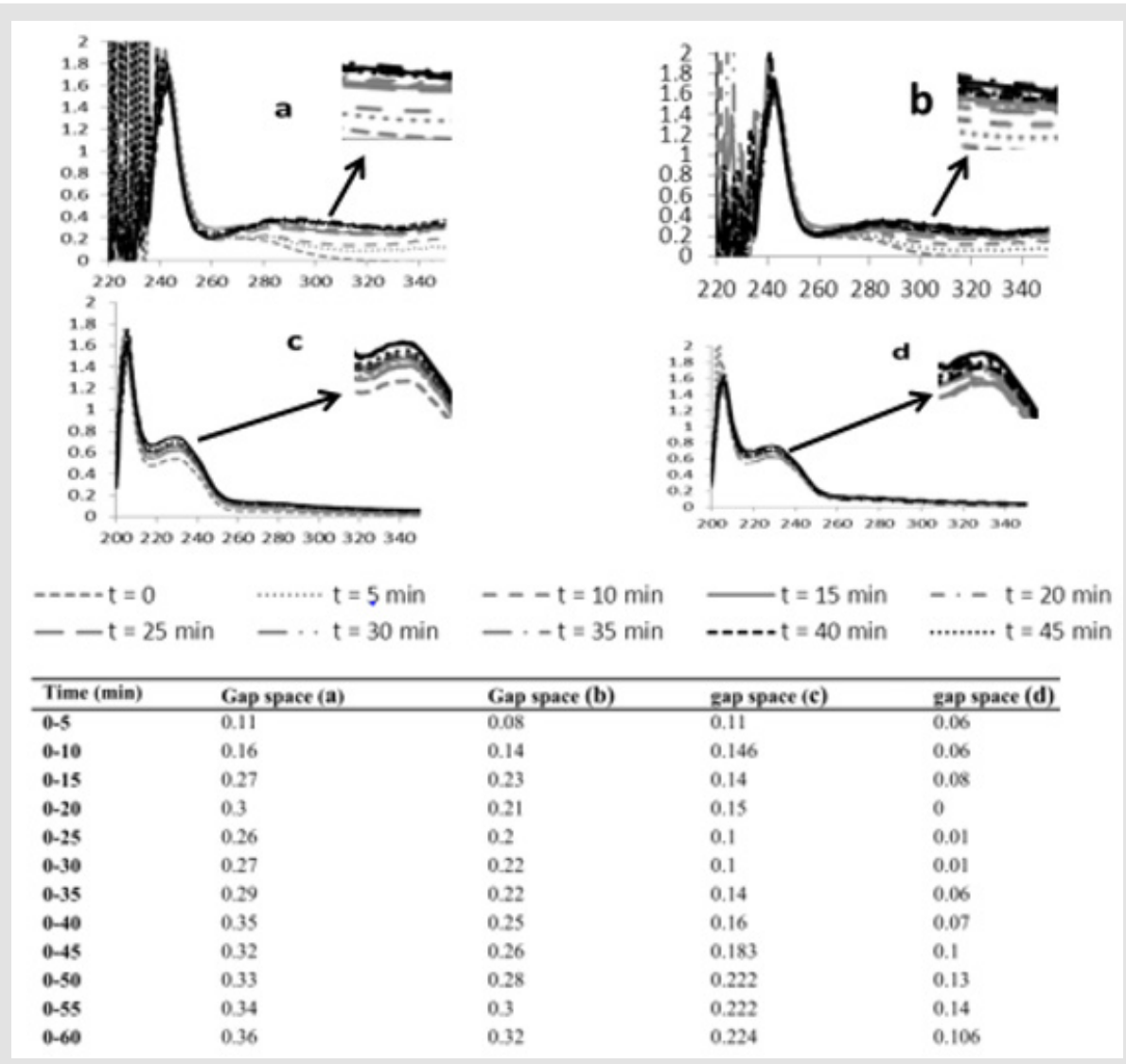

Figure 1: UV-visible spectra and gap spaces of (a) Oleic acid oxidation process by $\mathrm{OH} \bullet$. (b) Oleic acid oxidation process in the presence of dill. (c) Oleic acid oxidation process by $\mathrm{H}_{2} \mathrm{O}_{2}$ (d) oleic acid oxidation process by $\mathrm{H}_{2} \mathrm{O}_{2}$ in the presence of dill.

Also, in the presence of $\mathrm{N}^{3}$-, which is a well-known (Figure 2) singlet oxygen scavenger [32] conversion was inhibited (Table 1 , entry 5). In the presence of $\mathrm{NaN}_{3}$ - degradation of the porphyrin sensitizers was also inhibited. Table 1 entry 6 indicates that in the presence of DMSO conversion of oleic acid considerably diminished. Singlet oxygen lifetime is the important issue for gaining efficient yield during photooxygenation. According to the literature singlet oxygen lifetime in DMSO is $19 \mu \mathrm{s}, 65 \mu \mathrm{s}$ in acetonitrile and $38 \mu \mathrm{s}$ in ethanol which was corresponded with the results in Table 1 (entry $3,6,7$ ) [33-35] (Seheme 1). One of the key issues to efficient photooxygenation is photosensitizer. Singlet oxygen generation by differ- ent photosensitizer and their reactions with the oleic acid obey the order of H2TPP > FeTPP > ZnTPP. Paramagnetic metals are claimed to quench singlet oxygen by energy transfer mechanism from oxygen to the low-lying d electron levels and have very short triplet lifetimes (Table 1, entry 9,10) [36]. Oleic acid photooxygenation in the presence of dill as an natural antioxidant has the finest effect on limiting or preventing of oxidation due to its flavonoids compounds which is the most important family of exogenous antioxidants (Table 1 entry 4,8) [37] singlet oxygen scavenger. c1 cc antioxidant (contains 1.12mg flavonoid). d 2 cc antioxidant (contains $2.24 \mathrm{mg}$ flavonoid Seheme 2).

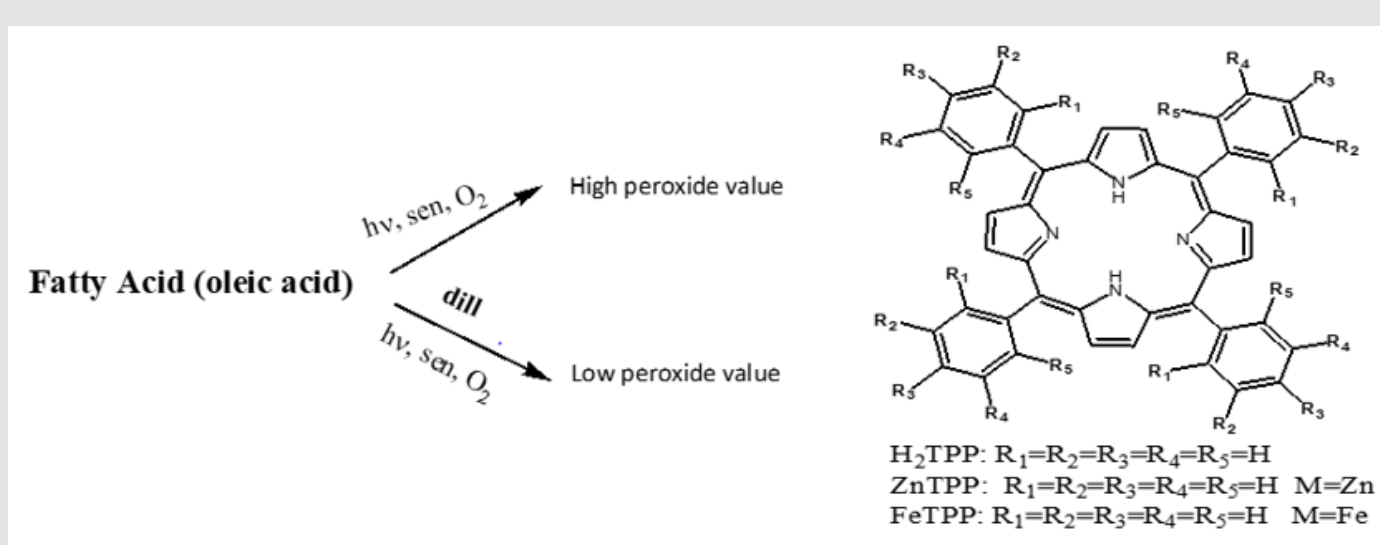

Scheme 1: Oleic acid photooxygenation in the presence and absence of antioxidant with photosensitizers (A). Structure of different applied photosensitizers (B). 


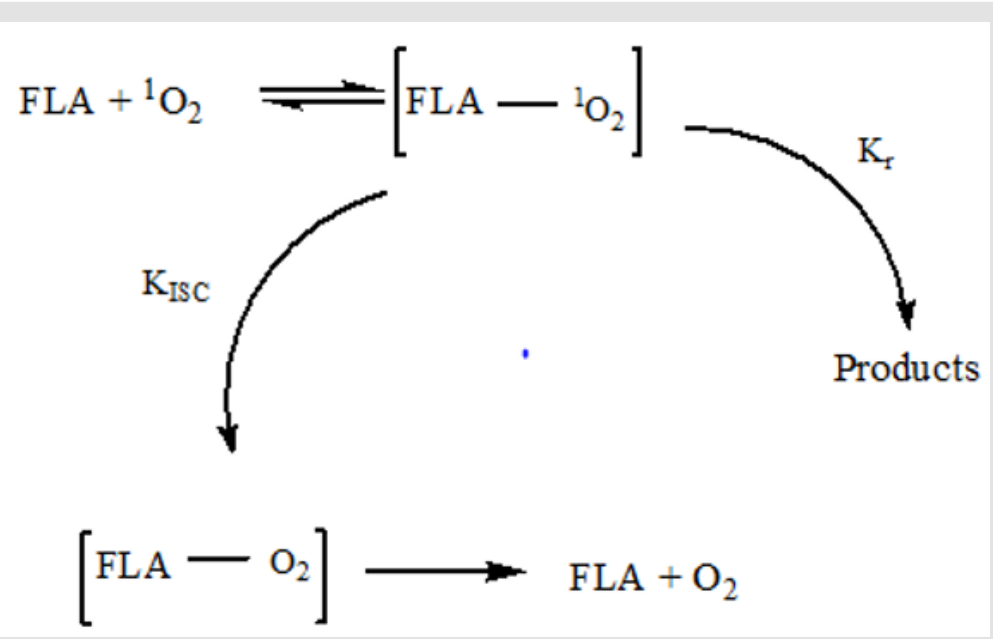

Scheme 2: The mechanism of flavonoids barricade against singlet oxygen.

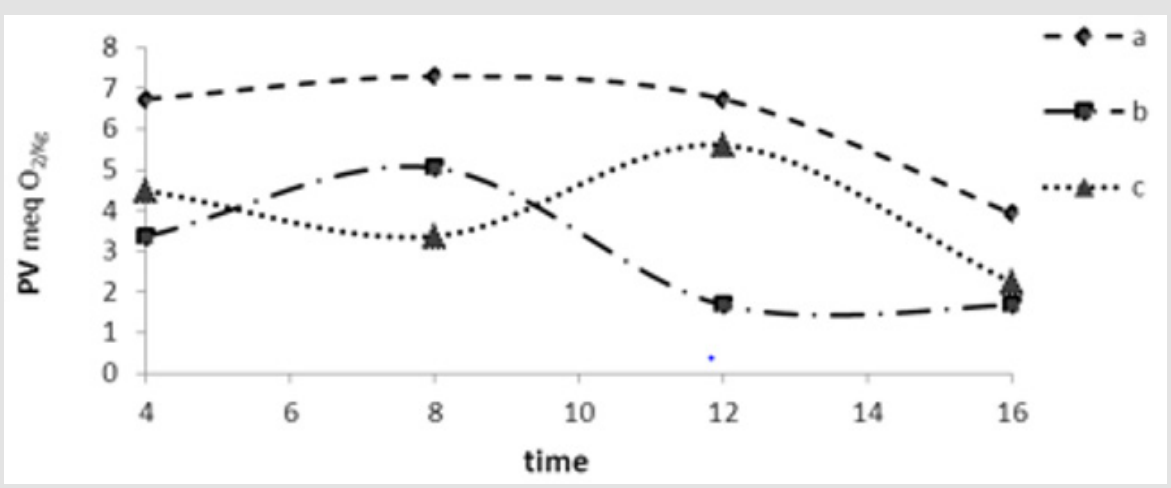

Figure 2: Oleic acid oxidation by superoxide anion radical in the absence of antioxidant (a), oleic acid oxidation in the presence of dill (contains $12.285 \mathrm{mg}$ polyphenolic compounds) (b) and oleic acid oxidation in the presence of vitamin $\mathrm{E}$ (contains $20 \mathrm{mg}$ natural alpha-tocopherol) (c)

As a result of daily life diet and the effect of different amount of natural antioxidant such as fruit, vegetable and herbals plants, our experience on dill showed how different amounts of dill as a natural antioxidant has efficient effect on restrict to produce peroxide as primary products. Results showed by increasing dill concentration the oleic acid oxidation rate or PV (meq $\mathrm{O}_{2} / \mathrm{kg}$ ) numbers were decreased (Table 1 entry 11,12). In the case of oxidation by radical hydroxyl $\mathrm{OH} \bullet$ and hydrogen peroxide $\mathrm{H}_{2} \mathrm{O}_{2}$, applied Uv-Vis method and idometric titration. Idometric as a popular method has limited and it is not an accurate method to measurable these ROS because of their peroxide agent. Although by extracting this oxidizing specie $\mathrm{PV}$ (meq $\mathrm{O}_{2} / \mathrm{kg}$ ) were calculated and dill showed that it is finest natural antioxidant to face with $\mathrm{H}_{2} \mathrm{O}_{2}$ after $1 \mathrm{~h}$ and $\mathrm{OH} \bullet$ after $3 \mathrm{~h}$ (Table 2 entry 1 and 2 for $\mathrm{H}_{2} \mathrm{O}_{2}$, entry 3 and 4 for $\mathrm{OH}^{\circ}$ ). Also, with UV-Vis method antioxidant property of dill was proved (Figure 2). According to the literature oxidation of polyunsaturated fatty acids is accompanied by an increase of absorption in the ultraviolet range (200-380nm). Lipids containing dienes or polyenes show a shift in their Double bond position during oxidation due to isomerization and conjugation formation [38]. In the presence of dill as an antioxidant the oxidation process by $\mathrm{OH} \bullet$ and $\mathrm{H}_{2} \mathrm{O}_{2}$ changed (Figure 1 column $\mathrm{b}$ and $\mathrm{c}$ ). Column a and $\mathrm{b}$ represent oleic acid absorption gap spaces at $\lambda=312 \mathrm{~nm}$ by $\mathrm{OH} \bullet$ and column $\mathrm{c}$ and $\mathrm{d}$ represent oleic acid oxidation absorption gap spaces at $\lambda=230 \mathrm{~nm}$ by $\mathrm{H}_{2} \mathrm{O}_{2}$ in the presence and absence of antioxidant after oxidation.

Table 2: The peroxide number (meq $\mathrm{O}_{2} / \mathrm{kg}$ ) of oleic acid oxidation by $\mathrm{H}_{2} \mathrm{O}_{2}$ and $\mathrm{OH}$.

\begin{tabular}{|c|c|c|c|c|}
\hline Entry & Conditions & Time= 1h & Time= 2h & Time $=3 \mathbf{3 h}$ \\
\hline 1 & oleic acid $+\mathrm{H}_{2} \mathrm{O}_{2}$ & 50.56 & 28.09 & Trace \\
\hline 2 & oleic acid $+\mathrm{H}_{2} \mathrm{O}_{2}+$ dill & 11.24 & 11.24 & 11.24 \\
\hline $3^{\text {b }}$ & oleic acid $+\mathrm{HO}$. & 21.86 & 5.62 & 16.86 \\
\hline $4^{\text {b }}$ & oleic acid + OH. +dill & 22.47 & 11.24 & Trace \\
\hline
\end{tabular}

${ }^{\mathrm{a}} 6.3 \times 10-3 \mathrm{~mol}$ oleic acid, 8cc ethanol, $0.1 \mathrm{cc}_{2} \mathrm{O}_{2}(30 \%)$, $2 \mathrm{cc}$ dill antioxidant (contains $8.19 \mathrm{mg}$ polyphenolic compounds ).

${ }^{\mathrm{b}}$ The reactions were irradiated by UV light from a high pressure $30 \mathrm{~W}$ mercury lamp (Philips, $=200-280 \mathrm{~nm}$ ).

These results showed that in the presence of dill as an antioxidant absorption gap spaces per $5 \mathrm{~min}$ is less than absorption gap spaces in the absence of dill for 1 hour oxidation which demonstrated dill has good effect on control of oxidation because of its polyphenol composition and antioxidant activity [39]. Also comparative of UVvis and iodometric data have been good agreement in the oxidation 
process. Our investigation of superoxide anion radical was based on $\mathrm{PV}\left(\mathrm{meqO}_{2} / \mathrm{kg}\right.$ ) (Figure 2). Lack of willingness oleic acid reaction by superoxide anion radical caused monitoring of products at longer period [40]. Results showed dill had the best effect on limitation of oleic acid oxidation during the $12 \mathrm{~h}$ oxidation and its antioxidant effect on $\mathrm{O}_{2} \bullet$ is more efficient than vitamin $\mathrm{E}$ as one of the best well known lipid soluble antioxidant.

\section{Conclusion}

Increase of diseases such as cancer, Alzheimer's disease, skin disorders, etc. because of human bad lifestyle and their incorrect eating habit turns broaden our view on using new, safe and none side effect medicine such as herbal and planet source. In this study it was showed dill has an efficient effect as a natural antioxidant on restricting or limitation oxidation fatty acid by different toxic ROS. In fact, dill had high antioxidant capacity for inhibition of $10_{2}$ and the other ROS.

\section{Acknowledgement}

We gratefully acknowledge support from the Kharazmi University.

\section{References}

1. Luis A, Sandalio LM, Corpas FJ, PalmaJM, Barroso JB, et al. (2006) Reactive Oxygen Species and Reactive Nitrogen Species in Peroxisomes. Production, Scavenging, and Role in Cell Signaling. Plant Physiol 141(2): 330-335.

2. Mates JM (2000) Effects of antioxidant enzymes in the molecular control of reactive oxygen species toxicology. Toxicology 153(1-3): 83-104.

3. Kinnula VL, Crapo JD, Free Radical Bio Med (2004) Kinnula VL, Crapo JDSuperoxide dismutases in malignant cells and human tumors 36: 718744.

4. Singh U, Jialal I (2006) Pathophysiology 13:129-142.

5. Ani V, Varadaraj MC, Naidu KA (2006) Antioxidant and antibacterial activities of polyphenolic compounds from bitter Cumin. Eur Food Res Technol 224: 109-115

6. Kobayashi Y, Nakano Y, Inayama K, Sakai A, Kamiya T (2003) Dietary intake of the flower extracts of German Chamomile (Matricaria recutita L) inhibited compound 48/80-induced itch-scratch responses in mice. Phytomedicine 10(8): 657-664.

7. Matos FJA, Machado MIL, Alencar JW, Craveiro AA (1993) Constituents of Brazilian chamomile oil. J Essent Oil Res 5: 337-339.

8. Duh PD, Yeh DB, Yen GC (1992) Pharmacological Potential of Matricaria recutita-A Review. J Am Oil Chem Soc 69: 814-818.

9. Cho ML, Ko SB, Kim JM (2016) Appl Biol Chem 59: 329-336.

10. Shrestha S, Boo KH, Cho SK (2015) Evaluation of antioxidant potential of ethyl acetate fraction of Rosmarinus officinalis L. and its major components. Appl Biol Chem 58(1): 715-722.

11. Grice HC (1988) Safety evaluation of butylated hydroxyanisole from the perspective of effects on forestomach and oesophageal squamous epithelium. Food Chem Toxicol 26(8): 717-723.

12. Wichi HC (1986) Enhanced tumour development by butylated hydroxytoluene (BHT) in the liver, lung and gastro-intestinal tract. Food Chem Toxicol 24(11): 1127-1130.

13. Koski A, Psomiadou E, Tsimidou M, Hopia A, Kefalas P, et al. (2002) Oil Eur Food Res 214: 294-298.
14. Hamid AA, Aiyelaag be O0, Usman LA, Ameen OM, Lawal A (2010) Pure Appl Chem 4: 142-151.

15. Bruneton J (1995) Process for the Preparation of Chromones, Isoflavones and Homoisoflavones Using Vilsmeier Reagent Generated from Phthaloyl Dichloride and DMF. Pharmacognosy, phytochemistry medicinal plants. Lavoisier publishing.

16. Choi MH, Lee IK, Kim GW, Kim BU, Han YH, et al. (2005) Regulation of PDGF signalling and vascular remodelling by peroxiredoxin II. Nature 435(7040): 347-353.

17. Forman HJ, Torres M (2002) Reactive oxygen species and cell signaling: respiratory burst in macrophage signaling. Am J Respir Crit Care Med 166(12): 4-8.

18. Morrell CN (2008) Reactive Oxygen SpeciesCirc Res 103(1): 571-572.

19. Terao J, Minami Y, Bando N (2011) Singlet molecular oxygen-quenching activity of carotenoids: relevance to protection of the skin from photoaging. J Clin Biochem Nutr 48(1): 57-62.

20. Min DB, Boff JM (2002) Chemistry and Reaction of Singlet Oxygen in Foods. Compr Rev Food Sci Food Saf 1: 58-72.

21. De Rosa MC, Crutchley RJ (2002) Photosensitized singlet oxygen and its applications. Coord Chem Rev 233: 351-371.

22. Greer A (2006) Christopher Foote's Discovery of the Role of Singlet Oxygen [102 (1 $\Delta \mathrm{g})]$ in Photosensitized Oxidation Reactions. Acc Chem Res 39(1): 797-804.

23. Hajimohammadi M, Vaziri Sereshk A, Schwarzinger C and Knör G (2018) Suppressing effect of 2-nitrobenzaldehyde on singlet oxygen generation, Fatty Acid Photooxidation, and Dye-Sensitizer Degradation. Antioxidants 7: 194.

24. Hajimohammadi M, Nosrati P (2018) Scavenging effect of pasipay (passiflora incarnate L.) on singlet oxygen generation and fatty acid photooxygenation. Food Science \& Nutrition 6: 1670-1675.

25. Hajimohammadi M, Safari N, Mofakham H, Deyhimi F (2011) Highly efficient, green and solvent-free photooxygenation of alkenes by air and visible light or sunlight in the presence of porphyrin sensitizers. Green Chem 13: 991-997.

26. Hajimohammadi M, Ahamadi Khamesi Z, Nosrati P (2109) Efficient aerobic photooxygenation of aldehydes to carboxylic acids using cobalt (II) phthalocyanine sulfonate as a photosensitizer in organic-water biphasic media. Transition Metal Chemistry 44: 167.

27. Kramarenko GG, Hummel SG, Martin SM, Buettner GR (2007) J Photochem Photobiol 82: 1634-1637.

28. Decker EA (1995) The role of phenolics, conjugated linoleic acid, carnosine, and pyrroloquinoline quinone as nonessential dietary antioxidants. Nutr Rev 53(3): 49-58.

29. Lindsey JS, Wagner RW (1989) Investigation of the synthesis of orthosubstituted tetraphenylporphyrins. J Org Chem 54(1): 828-836.

30. Su L, Yin JJ Charles D, Zhou K, Moore J, Yu L (2007) Total phenolic contents, chelating capacities, and radical-scavenging properties of black peppercorn, nutmeg, rosehip, cinnamon and oregano leaf [2007]. Food Chemistry 100: 990-997.

31. Barthel G, Grosch W (1974) Peroxide value determination-Comparison of some methods J Am Oil Chem Soc 51(6): 540-54).

32. Harbour JR, Issler SL (1982) J Am Chem Soc 104: 903-905.

33. Chen Y, Xu, S, Li L, Zhang M, Shen J, Shen T (2001) Dyes and Pigments 51: 63-69.

34. Bressan M, Morvillo A (1989) Alkene epoxidation by ruthenium (II) phosphine complexes. A kinetic investigation. Inorg Chem 28(5): 950953.

35. Toffoli DJ, Gomes LR, Junior NDV, Courrol LC, Wetter NU, et al. (2008) Aip Conf Proc 992: 1207-1212. 
36. Bonnett R, Martinez G (2001) Tetrahedron Lett 57: 9513.

37. Shyu YS, Lin JT, Chang YT, Chiang CJ, Yang DJ (2009) Food Chem 115: 515-521.

38. Vieira TM (1999) Identification of Character Impact Odorants of Different Soybean Lecithins J Agr Food Chem 47(7): 2203-2206.

\section{ISSN: 2574-1241}

DOI: 10.26717/BJSTR.2019.21.003650

Mahdi Hajimohammadi. Biomed J Sci \& Tech Res

(C) This work is licensed under Creative

Submission Link: https://biomedres.us/submit-manuscript.php
39. Rebey IB, Zakhama N, Karoui, IJ, Marzouk B (2012) Development and Application of a Database of Food Ingredient Fraud and Economically Motivated Adulteration from 1980 to 2010. J Food Sci 77: 34-39.

40. Augusto O, Miyamoto S (2011) Oxygen radicals and related species. Nova Science Publishers, New York, USA.

$\begin{array}{ll}\text { BIOMEDICAL } & \text { Assets of Publishing with us } \\ \text { RESEARCHES } & \text { - Global archiving of articles } \\ & \text { - Immediate, unrestricted online access } \\ & \text { - Rigorous Peer Review Process } \\ \end{array}$

